\title{
Correction to: Joint optimisation of drone routing and battery wear for sustainable supply chain development: a mixed-integer programming model based on blockchain-enabled fleet sharing
}

Yang Xia ${ }^{1,2} \cdot$ Wenjia Zeng ${ }^{1,2} \cdot$ Xinjie Xing $^{3}(D)$ Yuanzhu Zhan ${ }^{4} \cdot K_{i m}$ Hua $\operatorname{Tan}^{5}$. Ajay Kumar ${ }^{6}$

๑ Springer Science+Business Media, LLC, part of Springer Nature 2021

\section{Correction to: Annals of Operations Research https://doi.org/10.1007/s10479-021-04459-5}

This erratum is published as article as author affiliations were overlooked during proofing.

Affiliation Xinjie Xing should be read as Management School, University of Liverpool, Liverpool, UK as per original submission.

Original article has been updated.

Publisher's Note Springer Nature remains neutral with regard to jurisdictional claims in published maps and institutional affiliations.

The original article can be found online at https://doi.org/10.1007/s10479-021-04459-5.

$\triangle \quad$ Xinjie Xing

x.xing3@liverpool.ac.uk

1 Research Center for Modern Logistics, Shenzhen International Graduate School, Tsinghua University, Shenzhen 518055, China

2 Department of Industrial Engineering, Tsinghua University, Beijing 100084, China

3 Management School, University of Liverpool, Liverpool, UK

4 Birmingham Business School, University of Birmingham, Birmingham, UK

5 Nottingham University Business School, University of Nottingham, Nottingham, UK

6 AIM Research Centre on Artificial Intelligence in Value Creation, EMLYON Business School, Ecully, France 